\title{
Lamellation of the diploe in the skulls of patients with sickle cell anaemia
}

\author{
A. OLUFEMI WILLIAMS, S. B. LAGUNDOYE, and C. LENT JOHNSON \\ From the Departments of Pathology and Radiology, University of Ibadan, Nigeria, and the Orthopaedic \\ Branch of the Armed Forces Institute of Pathology, Washington, D.C.
}

\begin{abstract}
Williams, A. O., Lagundoye, S. B., and Johnson, C. L. (1975). Archives of Disease in Childhood, 50, 948. Lamellation of the diploe in the skulls of patients with sickle cell anaemia. This study describes the radiological and pathological findings in a necropsy series of 70 skulls of Nigerian patients with sickle cell gene, and 70 controls matched for sex and age with no sickle cell gene. $6(35 \%)$ of the 17 patients with sickle cell anaemia, or $17 \%$ of 35 patients with sickle cell gene excluding the trait, all under age 10 years, were shown to have bone trabeculae within the diploe arranged in stripes parallel to the curvature of the cranial tables on radiography. Histological examination of the skulls with curvilinear stripes showed long trabeculae of bone within the diploe similarly arranged in parallel rows but joined at variable intervals by short bridges of bone. The radiolucent areas between trabeculae corresponded to areas of marrow hyperplasia.

A skull radiograph in an African child presenting with this radiological sign should raise the suspicion of sickle cell disease.
\end{abstract}

In sickle cell disease the trabecular pattern within the diploe may sometimes be arranged perpendicularly to the curvature of the cranial vault to produce the appearance referred to as the hair-onend appearance. While this is a common finding in thalassaemia, it is rare in sickle cell disease. On the other hand, an arrangement of the trabecular pattern parallel to the curvature of the vault is not uncommon in sickle cell anaemia patients (Lagundoye, 1970). This gives rise to the so-called intradiploic curvilinear lamellation or stripes or 'onion peel' lamellation (Lagundoye, 1970, 1975).

We have determined the frequency of lamellation of the diploe in the skulls of patients coming to necropsy with proven sickle cell disease, and have studied the histological appearance of skulls with this pattern with a view to elucidating the mechanism of its production.

\section{Materials and methods}

The cranial vaults of 70 patients with sickle cell haemoglobinopathy, including sickle cell trait, who came to necropsy over a 3-year period, 1970-73, at the University College Hospital, Ibadan, were examined radiologically and histologically. The cranial vaults of

Received 11 March 1975.
70 patients matched for age and sex without sickle celic haemoglobinopathy but dying of a variety of other conditions during the same period were used as controls. The ages of the patients ranged from 1 day to $\mathbf{4 8}$ years. Their age and sex distribution according to their haemoglobin genotypes is summarized in the Table. Haemoglobin genotype was dutermined by paper electrophoresis during life and confirmed by the same method on blood obtained at necropsy.

The skulls were $x$-rayed in coronal and lateral positions, examined grossly, and fixed in $10 \%$ formalin. Sections were taken from the frontal, parietal, and occipital bones of the skulls with a thin electric saw blade. The bone specimens were decalcified and embedded in paraffin and stained with haematoxylin and eosin. The $x$-rays were read (S.B.L.) without knowledge of the haemoglobin electrophoretic pattern, and the histological appearances were described without knowledge of the radiological findings.

\section{Results}

Curvilinear lamellation or 'onion-peel' lamellation of the diploe (Fig. 1) was seen radiologically in only 6 patients, all aged 2-7 years; all of whom were Hb-SS patients, i.e. $35 \%$ of the 17 homozygous sickle cell (SS) disease patients in the series, or $17 \%$ of 35 patients with abnormal haemoglobin excluding the 35 with sickle cell trait. In 2 of 
TABLE

Age and sex distribution of subjects according to haemoglobin electrophoresis

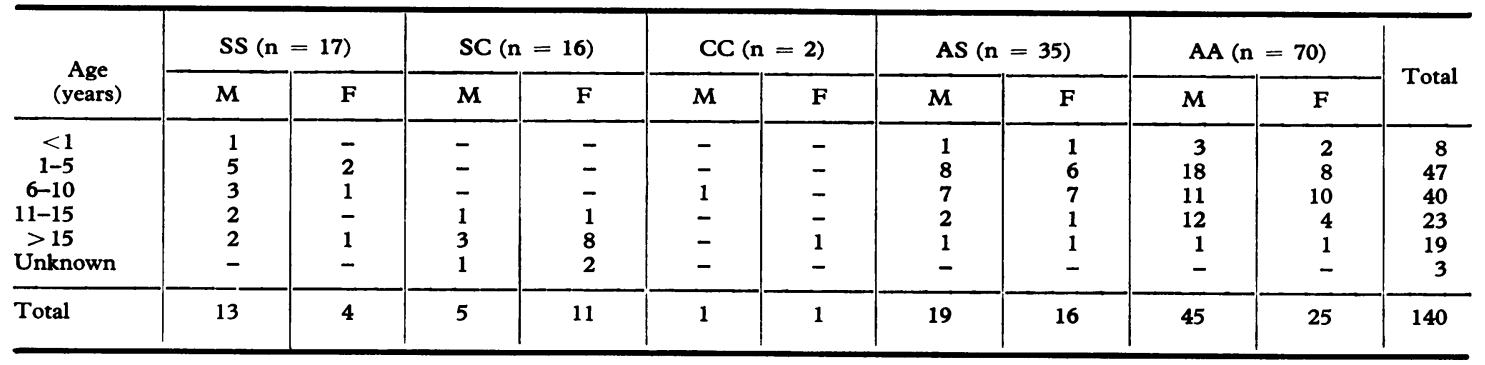

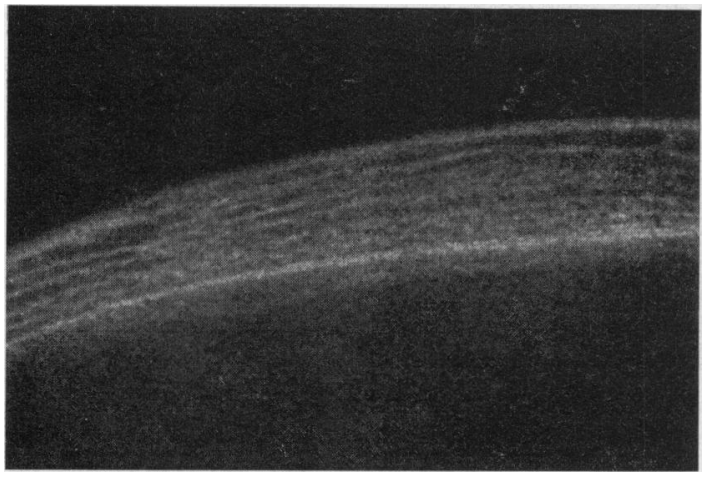

FIG. 1.-Close-up view of the $\mathrm{x}$-ray of the vault in a $\mathrm{Hb}-\mathrm{SS}$ patient. Note the radiological appearance of the curvilinear stripes of bone within the diploe which run parallel to the curvature of the inner and outer tables.

these cases the lamellation or curvilinear bone stripes were of very short lengths.

The remaining 53 cases with abnormal haemoglobin other than SS (namely, genotypes AS, SC, and CC), and the 70 controls with normal haemoglobin (i.e. genotype AA) showed no curvilinear stripes within the diploe, nor was hair-on-end appearance (Fig. 2) seen. During the period of study we encountered no cases of sickle thalassaemia or thalassemia major at necropsy.

Microscopically, the skull from normal patients showed a typical honeycombed appearance with relatively moderate amounts of marrow elements. The inner and outer tables were of normal thickness and appeared continuous (Fig. 3). In the 6 patients with curvilinear stripes, there was slight thickening of the inner table, and the outer tables had a relatively normal overlying periosteum. Between the outer and inner tables there were several long, continuous bony trabeculae running almost parallel to one another but separated from each other by hypercellular islands of marrow.
A few bony bridges were seen to connect some of these long bony trabeculae, thus converting them into quadrangles in places (Fig. 4 and 5). Fragments of bone and varying numbers of sickled erythrocytes were occasionally seen within the islands of hypercellular marrow (Fig. 5). The bony trabeculae appeared viable judging by the presence of osteocytes within lacunae, but minimal osteoclastic activity was evident in some of the trabeculae.

The inner table of the skull was grossly thickened and appeared either fenestrated or discontinuous in places (Fig. 6). This was in contrast to what was seen in normal skulls (Fig. 3). Internal to the inner table were long, filiform strands of new bone formation in some cases (Fig. 4). In some areas there was thickening of the endostium of the skull and pachymeninges (Fig. 4).

In the two patients with sickle-cell anaemia who had radiographic evidence of partial curvilinear stripes, there was extensive fibrosis of the marrow with focal areas of granulation tissue. The areas of fibrosis were patchy and were interspersed by relatively well preserved bony trabeculae of diploic bone with hypercellular marrow (Fig. 7).

The foregoing indicates that the histological appearance of the lamellated diploe in sickle-cell anemia correlates with the radiological appearance. The radiolucent areas correspond to the areas of marrow hyperplasia, while the radiopaque areas correspond to the areas of parallel bone trabeculae dividing the diploe into laminated strips.

\section{Discussion}

Hair-on-end appearance, though a common feature of thalassaemia (Baker, 1964) and occasionally noted in iron deficiency anaemia (Britton, Canby, and Kohler, 1960; Burko, Mellins, and Watson, 1961), is rare in sickle cell disease (Lagundoye, 1970; Song, 1971) where it is found in only 


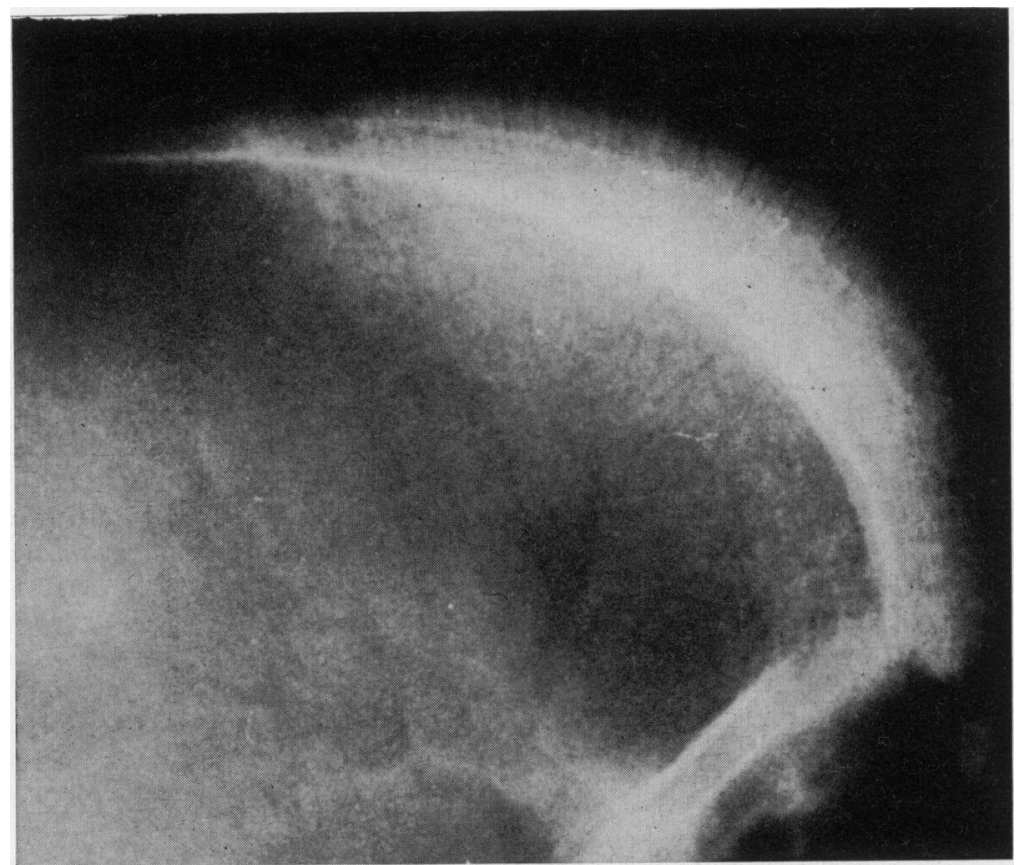

FIG. 2.-X-ray showing typical hair-on-end appearance in a patient known to have sickle cell anaemia. Note the vertical arrangement of the trabeculae within the thickened frontal diploe.

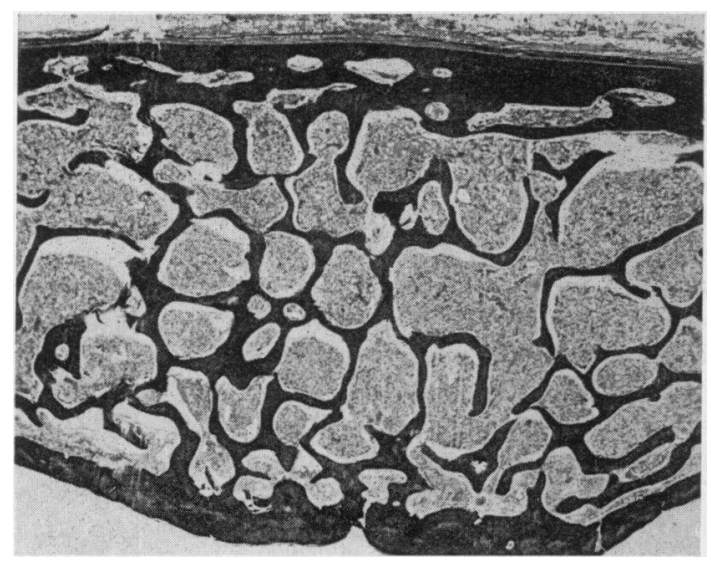

FIG. 3.-Microscopic appearance of normal diploe in a control patient. Note the normal thickness of inner and outer tables. $\times 8$.

about $5 \%$ of patients with SS disease (Diggs, 1973). The observed frequency of about $35 \%$ of diploic lamellation in this study, based on necropsy material, appears to confirm our previous subjective impression of its value as a radiological sign in sickle cell haemoglobinopathy. Since $x$-ray of

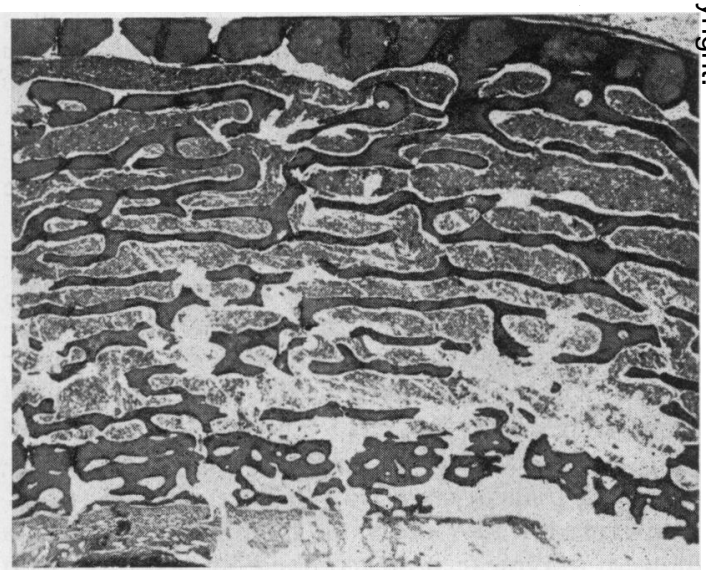

FIG. 4.-Microscopic appearance of diploic lamellation in frontal bone of patient in Fig. 1. Note the long trabeculae of bone running longitudinally and parallel to the tables. $\times 3$.

the necropsy specimen (Fig. 1) shows the lamellation more distinctly than in the living skull, a lower incidence rate will be expected in the latter, as cases will be missed except by an experienced observer. Furthermore, the 17 cases of $\mathrm{Hb}-\mathrm{SS}$ on 


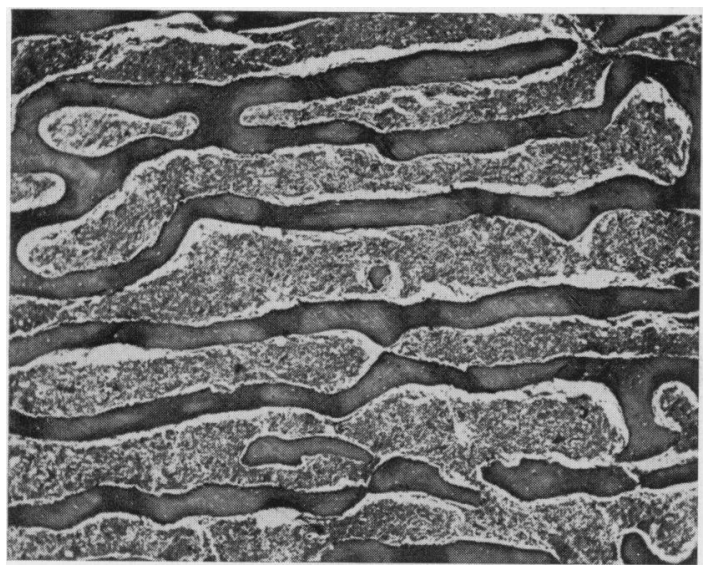

FIG. 5.- Higher power view of curvilinear stripes showing short bridges of bone converting the trabeculae into quadrangles. Note two small islands of bone in hypercellular marrow. $\times 30$.

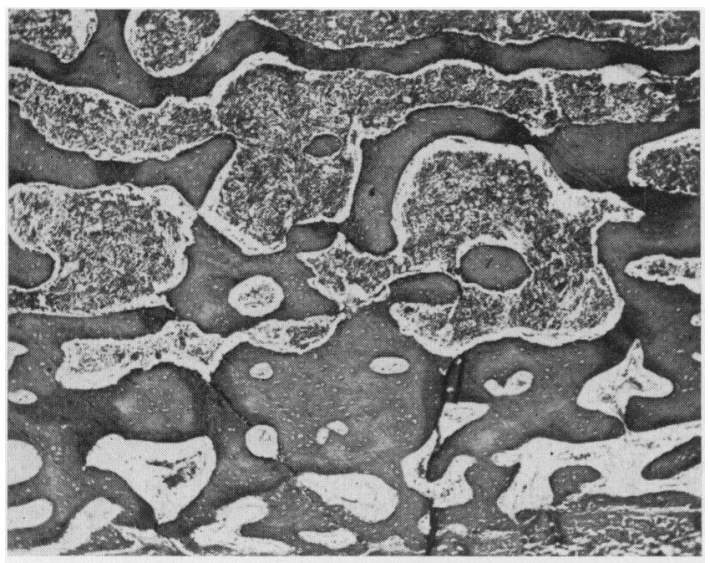

FIG. 6.-Microscopic appearance of inner table. Note marked thickening and irregularity and fenestration; also portion of thickened pachymeninges in the lower right corner, and presence of few trabeculae of new bone. $\times 30$.

which this incidence is based are too few, and a study to estimate the frequency of curvilinear lamellation of the diploe in the skull $x$-rays of patients with sickle cell anaemia, bearing in mind its prevalence in childhood as indicated in the present study, is in progress. It will also be interesting to follow up positive cases over some years and observe if and when the change disappears. The relative rarity of this change in skulls after the age of 10 years may be due to the fact that remodelling of mature diploic bones by hypercellular marrow may be more difficult

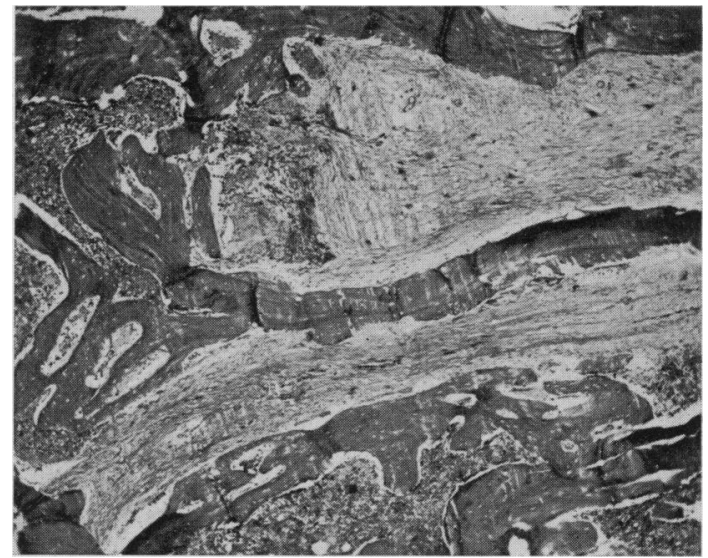

FIG. 7.-Microscopic appearance showing fibrosis in the marrow cavity within the diploe. Note the focal area of granulation tissue in the upper corner; this occasionally gives rise to the radiological appearance of focal curvilinear stripes. $\times 30$.

than that of the young immature diploic bones of early life. It is worth noting that diploic thickening and lamellation have been reported in children successfully treated for hydrocephalus (Loop and Foltz, 1972; Globl, Schut, and Kaufmann, 1973). One of us (S.B.L.) has encountered curvilinear lamellation of the diploe radiographically in 4 patients with normal haemoglobin genotype in Ibadan. These were 3 children with hydrocephalus and one with nutritional rickets all under age 10 years.

The exact mechanism of production of curvilinear stripes in the diploe is unclear. It appears that marrow hyperplasia is perhaps responsible for the parallel orientation of the bony trabeculae-an arrangement which would tend to accommodate hypercellular marrow elements more easily than the normal honey-comb diploic bone pattern. Extensive marrow infarction within the diploe may lead to regions of replacement fibrosis which may be another pathway for the evolution of this radiological and histological appearance (Fig. 7).

A skull $x$-ray in an African child (with no clinical evidence of hydrocephalus) which shows curvilinear diploic lamellation should raise the suspicion of sickle cell haemoglobinopathy with its implications for medical management.

The authors acknowledge the assistance of Mr. P. A. Olowa for the radiographs, Mr. Ishmael Nwabuebo for the histologic preparation, and Mr. Edwards of the A.F.I.P. for the photomicrographs. 


\section{REFBRENCBS}

Baker, D. H. (1964). Roentgen manifestations of Cooley's anemia. Annals of the New York Academy of Sciences, 119, 641.

Britton, H. A., Canby, J. P., and Kohler, C. M. (1960). Iron deficiency anemia producing evidence of marrow hyperplasia in the calvarium. Pediatrics, 25, 621.

Burko, H., Mellins, H. Z., and Watson, J. (1961). Skull changes in iron deficiency anemia stimulating congenital hemolytic anemia. American fournal of Reontgenology, Radivon Therapy, and Nuclear Medicine, 86, 447.

Diggs, L. W. (1973). Anatomic Lesions in Sickle Cell Diseases. Mosby, St. Louis.

Globl, H. J., Schut, L., and Kaufmann, H. J. (1973). Radiologic problems in patients operated for hydrocephalus. Annales de Radiologie, 16, 249.
Lagundoye, S. B. (1970). Radiological features of sickle cell anaemia and related haemoglobinopathies. African fournal of Medical Sciences, 1, 315.

Lagundoye, S. B. (1975). Radiology of sickle cell disease. $A$ Handbook for the General Clinician, p. 45. Caxton Press, Ibadan.

Loop, J. W., and Foltz, E. L. (1972). Cranio-stenosis and diploic lamination following operation for hydrocephalus. Acta Radiologica Diagnosis, 13, 8.

Song, J. (1971). Pathology of Sickle Cell Disease. Thomas, Springfield, Illinois.

Correspondence to Dr. A. Olufemi Williams, University of Ibadan and University College Hospital, Ibadan, Nigeria.

The following articles will appear in future issues of this journal:

Annotation: Population differences in body size, shape, and growth rate: a 1976 view. J. M. Tanner.

Mucocilliary transport in the trachea of patients with cystic fibrosis. D. B.Yeates, J. M. Sturgess, S. R. Khan, H. Levison, and N. Aspin.

Fatty change in the brain in perinatal and unexpected death. D. R. Gadson and J. L. Emery.

Growth patterns and nutrition in Nepali children. S. M. Farquharson.

Thoughts on the treatment of strawberry naevi. $R$. S. Illingworth.

Contribution of fibreoptic endoscopy to diagnosis and management of children with gastro-oesophageal reflux.

$P$. P. Forget and M. Meradji.

Development of CNS leukaemia in acute myeloid leukaemia in childhood. H. E. M. Kay.

Relation of urinary total hydroxyproline: creatinine ratio to height velocity in children with retarded growth.

S. Edwards, M. Hartog, C. A. Pennock, and J. Apley. 